\title{
Do we still need pharmacological stress ulcer prophylaxis at the ICU?
}

\author{
Lukas Buendgens, Frank Tacke \\ Department of Medicine III, University Hospital Aachen, Aachen, Germany \\ Correspondence to: Frank Tacke, MD, PhD. Department of Medicine III, RWTH-University Hospital Aachen, Pauwelsstrasse 30, 52074 Aachen, \\ Germany. Email: frank.tacke@gmx.net. \\ Provenance: This is an invited Editorial commissioned by Section Editor Dr. Xue-Zhong Xing [National Cancer Center (NCC)/Cancer Hospital, \\ Chinese Academy of Medical Sciences (CAMS) and Peking Union Medical College (PUMC), Beijing, China]. \\ Comment on: Alhazzani W, Guyatt G, Alshahrani M, et al. Withholding Pantoprazole for Stress Ulcer Prophylaxis in Critically Ill Patients: A Pilot \\ Randomized Clinical Trial and Meta-Analysis. Crit Care Med 2017;45:1121-9.
}

Submitted Sep 20, 2017. Accepted for publication Sep 20, 2017.

doi: $10.21037 /$ jtd.2017.09.121

View this article at: http://dx.doi.org/10.21037/jtd.2017.09.121

The gastric mucosa is vulnerable in critically ill patients. The term stress-related mucosal disease describes the common mucosal damage in the gastrointestinal tract ranging from small single lesions to multiple gastric ulcers and major bleeding complications in intensive care patients. The underlying pathophysiology comprises hemodynamic and inflammatory elements. Systemic factors (hypotension and/or vasopressor therapy) act together with local alterations of splanchnic blood flow, e.g., due to high ventilation pressures. This may not only cause direct ischemic damage but also leads to a reduction in gastric mucosal defense by inhibition of cyclooxygenase or lipoxygenase pathways and decline of prostaglandin levels (especially PGE2) (1).

Thus, stress ulcer prophylaxis has been an integral part of critical care and is recommended by current guidelines (2) in order to avoid gastrointestinal bleeding. Pharmacological stress ulcer prophylaxis with proton pump inhibitors (PPI) or, less frequently, histamine 2 receptor antagonists (H2RA) is routinely used in intensive care units (ICU) around the world (3). At the same time, gastrointestinal bleedings are very rarely seen in critically ill patients at the ICU, even though risk factors such as anticoagulant and antiplatelet therapies might be more prevalent than decades ago $(3,4)$. However, the practice of routine pharmacological stress ulcer prophylaxis in critical care medicine has been needing thorough revision for a long time for three main reasons: (I) it is based on trials conducted more than 20 years ago $(5,6)$; since then, a lot has changed in critical care; (II) no trial ever established a survival benefit for stress ulcer prophylaxis; (III) there are rising concerns about infectious and other complications of stress ulcer prophylaxis. A recent publication by Alhazzani and coworkers describes the results of a proof-of-concept trial on ten ICUs, which compared placebo vs. PPI for stress ulcer prophylaxis, and, in addition, summarizes the available evidence in a metaanalysis (7). This work is a major step forward in generating updated scientific evidence regarding the current routine of administering acid-suppressing drugs at the ICU.

\section{Relevance of stress ulcer prophylaxis in light of advances in critical care medicine}

The evidence for the current practice of stress ulcer prophylaxis is based on work from about 2 decades ago. Several prospective trials at that time had revealed that pharmacological stress ulcer prophylaxis can effectively prevent gastrointestinal bleeding in critically ill patients, with the highest evidence for patients requiring mechanical ventilation for $>48 \mathrm{~h}$ or patients with coagulopathies $(1,8)$. However, over the last decades, our daily practice at the ICU underwent major changes. We now routinely minimize hypoperfusion states in patients by aggressive fluid resuscitation (9). This is facilitated by improved hemodynamic monitoring and implementation of more advanced methods in daily routine such as transpulmonal thermodilution and stroke volume variation analysis (10). Additionally, we learned that lower tidal volumes and lower plateau pressures improves outcome in ventilated patients (11). Especially high airway pressure is one of the key factors 
underlying impaired gastric perfusion and damage (1). All these changes have not only improved general outcome, but likely also affected the frequency of stress-related gastric damage, lesions and ulcers. Consequently, the rate of clinically relevant upper gastrointestinal bleedings from stress lesions have significantly decreased in the past (12).

Moreover, we now understand much better that patients benefit from early enteral nutrition; this is incorporated into updated algorithms and daily practice (13). Besides other effects, enteral nutrition promotes mesenteric perfusion and protects the gastric and intestinal mucosa in critically ill patients (14). Accordingly, retrospective studies found no benefit for pharmacological gastric ulcer prophylaxis in enterally fed patients (15).

\section{Survival benefit as the ultimate outcome of prophylactic measures at the ICU}

In weighing risks and benefits of an intervention, especially a prophylactic one, survival benefit would be the desirable ultimate goal. While several older trials could demonstrate a reduction in bleeding incidence in patients receiving pharmacological stress ulcer prophylaxis, none could ever connect it to an improved survival (1). This fact is striking, because patients experiencing a clinically relevant upper gastrointestinal bleeding do show increased mortality rates (16). Thus, it remains unclear if gastrointestinal bleedings during the course of critical illness are prognostically relevant events per se or epiphenomena of disease severity. In addition, improved endoscopic and radiological embolization techniques tremendously changed the management in case of overt gastrointestinal bleedings, further reducing the mortality related to gastrointestinal hemorrhages. For instance, in a large retrospective analysis (7,376 ICU patients) from our own center, only $44(0.6 \%)$ developed gastrointestinal bleedings at the ICU $(0.6 \%)$, of which only 2 $(0.003 \%)$ could not be sufficiently controlled (17).

\section{Risks of routine PPI administration at the ICU}

The gastric acid is a natural barrier against pathogens. Acid suppression by pharmacological stress ulcer prophylaxis removes this barrier and allows colonization of the stomach. Hence, many investigations-although mainly from observational studies-found increased rates of infectious complications in critically ill patients receiving stress ulcer prophylaxis, primarily Clostridium diffcile associated colitis (18) and nosocomial pneumonia (19). Further concerns, raised from large observations in the general population, include that PPI might be associated with adverse cardiovascular events, independently of clopidogrel use (20), as well as with osteoporosis (1). Additionally, PPI favor intestinal colonization with multi-resistant bacteria such as vancomycin-resistant Enterococcus faecium (VRE) or multiresistant Klebsiella pneumonia (21). Additional risks at the ICU are the potential toxicity of PPI to the liver and the bone marrow as well as drug-drug-interactions (1).

\section{Scientific evidence from recent clinical trials}

Considering the limitations of the current evidence underlying the clinical practice of pharmacological stress ulcer prophylaxis and the outstanding relevance of this topic in critical care medicine, there is a clear need for new, robust and reliable scientific evidence. Fortunately, those data are now slowly arriving (Table 1). In the singlecenter randomized double-blind exploratory POP-UP trial $(n=214)$, no difference between pantoprazole and placebo was noted in mechanically ventilated patients regarding either bleeding or infectious complications (22). Another more recent prospective, double-blind, randomized and placebo-controlled trial $(\mathrm{n}=102)$ found no difference in bleeding complications, when pantoprazole or placebo was used in addition to enteral nutrition in mechanically ventilated patients (23).

Alhazzani et al. have now taken the next step to build better evidence. In their REVISE pilot trial, they demonstrate the feasibility of a randomized, international, double-blinded and multicenter trial investigating the effect of pantoprazole $v$ s. placebo in mechanically ventilated patients (7). Their reported pilot data from 49 patients on pantoprazole compared with 42 patients on placebo revealed even higher number of clinically relevant bleedings ( 3 vs. 2 , or $6.1 \%$ vs. $4.8 \%$, respectively) in the pantoprazole treatment arm. Hospital or overall mortality did not show significant differences. Furthermore, there was a trend towards reduced infectious complications in placebo-treated patients (7). In principle, these pilot data are reassuring that withdrawing pantoprazole from ICU patients is feasible and not associated with an eminent high risk of gastrointestinal bleedings or mortality. A large prospective trial from this group of investigators is currently running and recruiting. In addition, with the SUP-ICU trial by Krag and colleagues, a second large multicenter trial is underway (24). 
Table 1 Comparison of results from two recent randomized controlled clinical trials comparing placebo vs. pantoprazole (40 mg, i.v. daily) for stress ulcer prophylaxis in critically ill patients

\begin{tabular}{|c|c|c|c|c|c|c|}
\hline Variables & \multicolumn{3}{|c|}{ POP-UP (22) } & \multicolumn{3}{|c|}{ REVISE (7) } \\
\hline Patient number & 106 & 108 & - & 49 & 42 & - \\
\hline Age (mean \pm SD) (years) & $52 \pm 18$ & $52 \pm 17$ & n.s. & - & - & - \\
\hline Age [median (IQR)] (years) & - & - & - & $61.8(8.4-73.5)$ & $55.3(42.4-65.6)$ & n.s. \\
\hline Surgical vs. medical, $\mathrm{n}[\%]$ & $\begin{array}{l}31 \text { vs. } 75 \\
{[29 \text { vs. } 71]}\end{array}$ & $\begin{array}{c}32 \text { vs. } 76 \\
{[30 \text { vs. } 70]}\end{array}$ & n.s. & $\begin{array}{c}10 \text { vs. } 39 \\
{[20 \text { vs. } 80]}\end{array}$ & $\begin{array}{c}11 \text { vs. } 31 \\
{[26 \text { vs. } 74]}\end{array}$ & n.s. \\
\hline Enteral feeding, $\mathrm{n}[\%]$ & 94 [87] & 88 [83] & n.s. & $81[89]$ & - & - \\
\hline Clinically significant bleeding, n (\%) & $0(0)$ & $0(0)$ & n.s. & $3(6.1)$ & $2(4.8)$ & n.s. \\
\hline ICU mortality (\%) & - & - & - & $11 / 49(22.4)$ & 10/42 (23.8) & n.s. \\
\hline 90-day-mortality (\%) & $30 / 106(28.3)$ & 25/108 (23.1) & n.s. & - & - & - \\
\hline
\end{tabular}

CDAD, Clostridium difficile-associated diarrhea; ICU, intensive care unit; IQR, interquartile range; SD, standard deviation; VAP, ventilatorassociated pneumonia; n.s., not significant.

\section{Conclusions}

At the moment, the current practice of routinely using pharmacological stress ulcer prophylaxis is being revised. While patients with defined risk settings for clinically relevant gastrointestinal bleedings may benefit from maintaining this strategy, the majority of ICU patients probably deserves an individualized risk-benefit assessment, which will likely result in withholding or early discontinuation of PPI in a large proportion of patients. It will be exciting to see the data from ongoing large trials and to revise our daily algorithms accordingly. The administration of a PPI is certainly not a risk-free prophylactic intervention, and we are only starting to apprehend some of the changes that they provoke in the intestinal microbiome and other anti-infective defense mechanisms of the body.

\section{Acknowledgements}

Funding: This work was supported by the German Research Foundation (DFG Ta434/5-1) and by the Interdisciplinary Center for Clinical Research (IZKF) Aachen.

\section{Footnote}

Conflicts of Interest: The authors have no conflicts of interest to declare.

\section{References}

1. Buendgens L, Koch A, Tacke F, et al. Prevention of stressrelated ulcer bleeding at the intensive care unit: Risks and benefits of stress ulcer prophylaxis. World J Crit Care Med 2016;5:57-64.

2. Rhodes A, Evans LE, Alhazzani W, et al. Surviving Sepsis Campaign: International Guidelines for Management of Sepsis and Septic Shock: 2016. Crit Care Med 2017;45:486-552.

3. Krag M, Perner A, Wetterslev J, et al. Prevalence and outcome of gastrointestinal bleeding and use of acid suppressants in acutely ill adult intensive care patients. Intensive Care Med 2015;41:833-45.

4. Koch A, Buendgens L, Dückers H, et al. Bleeding origin, patient-related risk factors, and prognostic indicators in patients with acute gastrointestinal hemorrhages requiring intensive care treatment. A retrospective analysis from 1999 to 2010. Med Klin Intensivmed Notfmed 
2013;108:214-22 .

5. Martin LF, Booth FV, Karlstadt RG, et al. Continuous intravenous cimetidine decreases stress-related upper gastrointestinal hemorrhage without promoting pneumonia. Crit Care Med 1993;21:19-30.

6. Metz CA, Livingston DH, Smith JS, et al. Impact of multiple risk factors and ranitidine prophylaxis on the development of stress-related upper gastrointestinal bleeding: a prospective, multicenter, double-blind, randomized trial. The Ranitidine Head Injury Study Group. Crit Care Med 1993;21:1844-9.

7. Alhazzani W, Guyatt G, Alshahrani M, et al. Withholding Pantoprazole for Stress Ulcer Prophylaxis in Critically Ill Patients: A Pilot Randomized Clinical Trial and MetaAnalysis. Crit Care Med 2017;45:1121-9.

8. Bardou M, Quenot JP, Barkun A. Stress-related mucosal disease in the critically ill patient. Nat Rev Gastroenterol Hepatol 2015;12:98-107.

9. PRISM Investigators, Rowan KM, Angus DC, et al. Early, Goal-Directed Therapy for Septic Shock - A Patient-Level Meta-Analysis. N Engl J Med 2017;376:2223-34.

10. Marx G, Schindler AW, Mosch C, et al. Intravascular volume therapy in adults: Guidelines from the Association of the Scientific Medical Societies in Germany. Eur J Anaesthesiol 2016;33:488-521.

11. Acute Respiratory Distress Syndrome Network, Brower RG, Matthay MA, et al. Ventilation with lower tidal volumes as compared with traditional tidal volumes for acute lung injury and the acute respiratory distress syndrome. N Engl J Med 2000;342:1301-8.

12. Plummer MP, Blaser AR, Deane AM. Stress ulceration: prevalence, pathology and association with adverse outcomes. Crit Care 2014;18:213.

13. Reintam Blaser A, Starkopf J, Alhazzani W, et al. Early enteral nutrition in critically ill patients: ESICM clinical practice guidelines. Intensive Care Med 2017;43:380-98.

14. Sim JA, Horowitz M, Summers MJ, et al. Mesenteric blood flow, glucose absorption and blood pressure responses to small intestinal glucose in critically ill patients older than 65 years. Intensive Care Med 2013;39:258-66.

15. Palm NM, McKinzie B, Ferguson PL, et al. Pharmacologic
Stress Gastropathy Prophylaxis May Not Be Necessary in At-Risk Surgical Trauma ICU Patients Tolerating Enteral Nutrition. J Intensive Care Med 2016. [Epub ahead of print].

16. Cook DJ, Fuller HD, Guyatt GH, et al. Risk factors for gastrointestinal bleeding in critically ill patients. Canadian Critical Care Trials Group. N Engl J Med 1994;330:377-81.

17. Koch A, Buendgens L, Dückers H, et al. Gastrointestinal bleeding in liver cirrhosis at the ICU. Z Gastroenterol 2013;51:19-25.

18. Buendgens L, Bruensing J, Matthes M, et al. Administration of proton pump inhibitors in critically ill medical patients is associated with increased risk of developing Clostridium difficile-associated diarrhea. J Crit Care 2014;29:696.e11-5.

19. MacLaren R, Reynolds PM, Allen RR, et al. Histamine-2 receptor antagonists vs proton pump inhibitors on gastrointestinal tract hemorrhage and infectious complications in the intensive care unit. JAMA Intern Med 2014;174:564-74.

20. Charlot M, Ahlehoff O, Norgaard ML, et al. Proton-pump inhibitors are associated with increased cardiovascular risk independent of clopidogrel use: a nationwide cohort study. Ann Intern Med 2010;153:378-86.

21. Stiefel U, Rao A, Pultz MJ, et al. Suppression of gastric acid production by proton pump inhibitor treatment facilitates colonization of the large intestine by vancomycin-resistant Enterococcus spp. and Klebsiella pneumoniae in clindamycin-treated mice. Antimicrob Agents Chemother 2006;50:3905-7.

22. Selvanderan SP, Summers MJ, Finnis ME, et al. Pantoprazole or Placebo for Stress Ulcer Prophylaxis (POP-UP): Randomized Double-Blind Exploratory Study. Crit Care Med 2016;44:1842-50.

23. El-Kersh K, Jalil B, McClave SA, et al. Enteral nutrition as stress ulcer prophylaxis in critically ill patients: A randomized controlled exploratory study. J Crit Care 2017;43:108-13.

24. Krag M, Perner A, Wetterslev J, et al. Stress ulcer prophylaxis with a proton pump inhibitor versus placebo in critically ill patients (SUP-ICU trial): study protocol for a randomised controlled trial. Trials 2016;17:205.
Cite this article as: Buendgens L, Tacke F. Do we still need pharmacological stress ulcer prophylaxis at the ICU? J Thorac Dis 2017;9(11):4201-4204. doi: 10.21037/jtd.2017.09.121 